\title{
Performance of Biochemical Compounds and Cup Quality of Arabica Coffee as Influenced by Genotype and Growing Altitude
}

\author{
Dwi Nugroho ${ }^{1 *}$, Panjisakti Basunanda' ${ }^{2}$, and Yusianto ${ }^{1)}$ \\ ${ }^{1)}$ Indonesian Coffee and Cocoa Research Institute, Jl. PB. Sudirman 90, Jember Indonesia \\ ${ }^{2)}$ Faculty of Agriculture, Gadjah Mada University, Jl. Flora, Bulaksumur, Jogjakarta, Indonesia \\ "Corresponding Author: dwinugroho.iccri@gmail.com \\ Received: 27 September 2019 / Accepted: 31 December 2019
}

\begin{abstract}
Arabica coffee (Coffea arabica) cultivation in the medium altitude (700$900 \mathrm{~m}$ above sea level, asl.) will face problems such as decreasing productivity, physical, biochemical and cup quality and increasing intensity of pest and disease attacks. Utilization of plant material that has good productivity and cup quality, resistance to pests and diseases is an effort that can be done to overcome these problems. The aims of this study is to evaluate performance of Arabica coffee quality grown at high and medium altitude area, as well as biochemical compound and cup quality changes that occur due to influence of genotypes and genotype $x$ altitude interactions. Eight genotypes of Arabica coffee were evaluated at two locations namely KP Andungsari (1,250 m asl.) and Kalibendo (700 m asl.). The field design for each location was randomized complete block design with three replicates. Observations were made on the two quality aspects, namely the biochemical compounds and cup qualities. The result on the biochemical compounds showed that the altitude significantly affect to the content of caffeine, sucrose, and trigonelline. Effect of genotype $\times$ altitude occured to the caffeine, trigonelline, and sucrose content. Diversity of chlorogenic acid content was caused by the genotype effect. Cup test results showed that genotypes grown at high altitude had a better cup quality than genotypes on medium altitude. Cup quality variables that were changed due to altitude difference were fragrance and aroma, flavor, aftertaste, acidity, balance, and overall, while the cup quality variable that did not changed was the body. Characters of coffee aroma at the high altitude were floral, spicy and fruity, while at the medium altitude were herbal, green and grassy. The best quality genotype at the high altitude was $\mathrm{K} 8$, while at the medium altitude was K29. Environment (altitude) gives greater influence to the formation of coffee flavor variations produced compared to genotypes.
\end{abstract}

Keywords: Arabica coffee, cup taste, physical, biochemical compounds, altitude

\section{INTRODUCTION}

Arabica coffee (Coffea arabica) is the most widely traded and consumed coffee in the world. According to Van der Vossen (2001), 70\% of the world coffee is Arabica, and the remaining is Robusta. Arabica production in 2012 reached 85.8 million bags
(58\%), while Robusta was only 62.2 million bags (42\% of total world coffee production) Anonim, (2014 a). Indonesian coffee production is in contrast to coffee production and consumption in the world. Indonesian coffee is dominated by Robusta $(79.21 \%)$ than Arabica (21.78\%), therefore Indonesia is well known as a Robusta producer (Anonim, 
2014 b). Arabica production increase will add more revenue because its price is higher than Robusta.

A production increase of Arabica can be done in two ways: intensification, meaning to increase coffee productivity per unit area of land by improving crop cultivation systems, and extensification, meaning to increase production by expanding the planting area. Production increase through intensification is considered relatively more difficult because naturally, Arabica tends to decrease in yield for one to two years after peak production or known as biennial bearings (Yahmadi, 1973). Actually, Arabica can grow and produce well in the high altitude (> 1,000 $\mathrm{m}$ asl.). Arabica extensification at an altitude of more than $1,000 \mathrm{~m}$ asl. is difficult to do because, in Indonesia, the availability of high land is very limited. Competitive commodities such as horticultural crops increasingly limit the availability of suitable land for Arabica coffee. Development land is still widely available on the medium altitude (700-900 $\mathrm{m}$ asl.), which is the minimum height still considered suitable for growing Arabica coffee (Hulupi, 2006). Arabica cultivation on medium altitude will face many problems, such as an increase in pest and disease attacks and decrease in the quality of the flavor (Hulupi, 2006). Following this situation, a special strategy is needed to get Arabica varieties that have good adaptability and flavor on medium altitude.

Leroy et al. (2006) explained four important components in coffee that greatly affect the quality of coffee: water content of beans, physical quality of beans, quality of flavor, and quality of plant health as indicated by the content of biochemical compounds which can affect plant health. Physical quality, flavor quality, and biochemical content are three important components influenced by plant genetic traits, cultivation practices/growing environment, and the interactions between both (Wintgens, 2004), while seed water content is only affected by post-harvest handling processes. Coffee as a refresher commodity, the quality of flavor is the ultimate goal of all cultivation and processing carried out to the coffee. The value of flavor quality is usually obtained from the results of organoleptic tests conducted by descriptive analysis by expert panelists.

Coffee flavor and aroma formed during the taste test are the results of a combination of hundreds of biochemical components produced by the reactions during the roasting process (Franca et al., 2005). The creation of coffee aroma is a complex process including Mailard \& Strecker reaction and temperature degradation during the roasting process. More than 800 volatile compounds combine to form the aroma of coffee (Dart \& Nursten, 1985; Flamen, 1989; Shibamoto, 1991), and many components are still unknown, including non-volatile compounds (Shibamoto, 1991). Fragrance precursors are compounds that play a role in producing new compounds of aroma, some have been successfully found such as sucrose and trigonelline (Clifford, 1985; Dart \& Nursten, 1985), chlorogenic acid and caffeine (Leloup et al., 1995), amino acids, organic acid peptides, fats, and carotenoids (Montavon et al., 2003). Caffeine and chlorogenic acid are phenol compounds produced by plants as secondary metabolites that have a function in the plant defense system against ultraviolet radiation or pests and diseases (Farah \& Donangelo, 2006).

The interaction between genotypes and the environment in coffee plants has been widely studied, but most focus on the results of agroforestry and agronomic traits that affect the yield (Wamatu et al., 2003; Demissie et al., 2011; Yonas et al., 2014). A study conducted by Lara-Estrada \& Vaast (2006) showed that the influence of the 
planting site height affects the physical quality of the beans, the quality of the flavor, and the biochemical composition of the coffee beans produced greater than the effect of cultivation practices such as shade and fertilization. Coffee planted at an altitude of more than $1,000 \mathrm{~m}$ asl. has aromatic characteristics, low bitterness, and good acidity and body, while the flavor of Arabica planted at an altitude less than $850 \mathrm{~m}$ asl. has a high bitterness, grassy, low aroma value, and tend to be astringent (Decazy et al., 2003). Likewise, Kassaye et al. (2016) reported that the increase in the height of Arabica cultivation from medium to high altitude with a difference of $400 \mathrm{~m}$ asl. rise caffeine content by $10 \%$. A study conducted by Gichimu et al. (2012) about the interaction of genotype $x$ environment on the flavor of Arabica coffee showed that there was a significant effect of genotype $x$ environment interaction in almost all flavor variables tested (fragrance, flavor, aroma, aftertaste, acidity, balance, preference, and total score) except for the body. However, the study was carried out in three locations with an altitude of 1,524; 1,554; and 1,700 $\mathrm{m}$ asl., so that the influence of genotypes and their interactions on an environment with a medium altitude (700$900 \mathrm{~m}$ asl.) cannot be explained.

This study aimed to determine the effects of genotype, environment, and interaction of genotype $x$ environment on the variables of biochemical components and the flavors of eight Arabica genotypes in different altitude and to determine the relationship between the biochemical variables and the observed flavors. The results of the study are expected to be a consideration for the feasibility of growing Arabica coffee in the medium altitude.

\section{MATERIALS AND METHODS}

\section{Time and Location}

This study was conducted in June-August of the 2014 harvest season. It was done at (1) Experimental Plantation of Andungsari (KP. Andungsari) (Testing code A1)Bondowoso and (2) Kalibendo Plantation (Testing code A2)-Banyuwangi. Andungsari Experimental Plantation is located at an altitude of 1,250 $\mathrm{m}$ asl., and according to Schmidt \& Ferguson (1951), the climate type is C-D, representing the high altitude. Kalibendo Plantation is located at an altitude of $700 \mathrm{~m}$ asl., according to Schmidt \& Ferguson, the climate type is A-B, representing the medium altitude region.

\section{Experimental Design}

The experimental design used at each location was a randomized complete block design with three blocks as replications. Each replication consisted of eight Arabica coffee genotypes (Table 1). BP 700 clone is the result of clonal selection from F1 hybrid with selection number KB II/61/3 and the parent tree is the result of an introduction with accession number C-1662-10-3. K8, K29, K34, K79, K99, and K130 genotypes which are genotypes of composite variety 'KOMASTI' (Komposit Andungsari 3) which have also been released based on the Decree of the Minister of Agriculture No.200/Kpts/ SR.120/1/2013 dated January 18, 2013. Total number of experimental units in two locations was 48 units, and each trial unit consisted of 20 plants grown into two rows. The spacing in rows was $2 \mathrm{~m}$, while the spacing between rows adjusted to the contour of the test plot (Table 1). 
Planting in KP. Andungsari was conducted in February 2009, while at Kalibendo Plantation in December 2008. The shade plant used in KP. Andungsari was Indigofera sp., while in Kalibendo Plantation used productive shade consisting of macadamia (Macadamia antegrofolia) and clove (Syzygium aromaticum). All coffee trees were maintained according to the standard cultivation requirements, such as inorganic fertilizers given at the recommended dosage twice a year, organic fertilizer was given once a year. Plants were maintained using a two-stage single-pruned pruning system, while pest control using pesticides, preferably using a healthy crop cultivation system.

Table 1. Arabica coffee genotypes tested

\begin{tabular}{ll}
\hline Genotype & \multicolumn{1}{c}{ Description } \\
\hline BP 700A/BP 308 & $\begin{array}{l}\text { Promising variety dwarf type selection } \\
\text { no. BP700A }\end{array}$ \\
K8 & $\begin{array}{l}\text { A composing genotype of composite } \\
\text { variety 'KOMASTI' }\end{array}$ \\
K29 & $\begin{array}{l}\text { A composing genotype of composite } \\
\text { variety 'KOMASTI' }\end{array}$ \\
K34 & $\begin{array}{l}\text { A composing genotype of composite } \\
\text { variety 'KOMASTI' }\end{array}$ \\
K79 & $\begin{array}{l}\text { A composing genotype of composite } \\
\text { variety 'KOMASTI' }\end{array}$ \\
K99 & $\begin{array}{l}\text { A composing genotype of composite } \\
\text { variety 'KOMASTI' }\end{array}$ \\
K130 & $\begin{array}{l}\text { A composing genotype of composite } \\
\text { variety 'KOMASTI' } \\
\text { Released variety result of participatory } \\
\text { breeding at North Sumatra }\end{array}$ \\
\hline
\end{tabular}

\section{Harvest and Post-harvest Processes}

Harvesting was carried out manually when the fruits are ripe. The ripening process of each genotype and in each location did not occur simultaneously, so the harvesting was done in several stages with a rotation 14 days in each location. The harvesting process were carried out for three months, between June-August 2014, until the number of samples is sufficient. The harvested berries were put in small sacks marked with a location code, a repetition, and a genotype.

The post-harvest process chosen was the wet process dry hulling. The pulp was removed using a manual pulper machine to avoid mixing the berries from each treatment. The coffee beans were then fermented for 12 hours. The harvest and post-harvest processes were continued until the harvest rotation completed.

After the rotation of the harvest ends, parchment coffee produced from each crop rotation was collected in one sack following the location code, replication, and genotype. Parchment beans collected were then hulled to get green bean then used as an experimental sample for testing.

\section{Observation}

Observations were made on the variables of the four biochemical compounds, then organoleptic tests (cup taste) were conducted at Cup Taste Laboratory of the Indonesian Coffee and Cocoa Research Institut. Biochemical component observations were carried out on four flavor precursors: (1) caffeine, (2) chlorogenic acid, (3) sucrose, and (4) trigonelline. Biochemical component observations were carried out using liquid chromatography-mass spectrometry (LCMS) based on a modified method from Nascimento et al. (2015).

Examples for cup taste profiles were obtained by roasting $150 \mathrm{~g}$ of green bean using a Probat sample roaster. Green bean was roasted on a medium roast level with a $65 \AA$ color standard. The roasted sample was pulverized using a grinder. Brewing was done by taking $10 \mathrm{~g}$ of ground coffee, then brewed water at a temperature of $90-100^{\circ} \mathrm{C}$. Each unit of the experiment was repeated five times (put in five bowls) to test uniformity.

Organoleptic test was carried out by a descriptive method, meaning each genotype with the same number was arranged in pairs between genotypes planted at high altitude and those planted at medium altitude. Randomiza- 
tion was carried out in each pair, so the panelists assessed objectively. This method also aimed to reduce errors due to subjectivity and physiological effects such as fatigue, hungry/ satiety, and emotional panelists so that the result data is more accurate.

Each sample was tested by three trained and certified panelists as cup taster panelists from the Indonesian Coffee and Cocoa Research Institute. The assessment process used a system developed by Lingle (1986 $a, b)$ of the Specialty Coffee Association (SCA) by giving a score between 1-10 on each variable. Variable observed include; fragrance and aroma, flavor, aftertaste, body, acidity, uniformity, sweetness, balance, clean cup, overall, and total score. Each sample tested also received comments from panelists to describe the flavors that were not represented by the checklist.

\section{Data Analysis}

Data analysis was done on each component of quality with different analytical methods adjusted for the study and expected results. The content of biochemical compounds was analyzed using combined analysis to determine the effect of genotype, environment, and interactions of genotype $\times$ environment. According to Neter et al. (1996) the combined analysis model of variance is

$$
Y_{i j k}=\mu+L_{i}+B_{k(i)}+G_{j}+(L G)_{i j}+E_{i j k}
$$

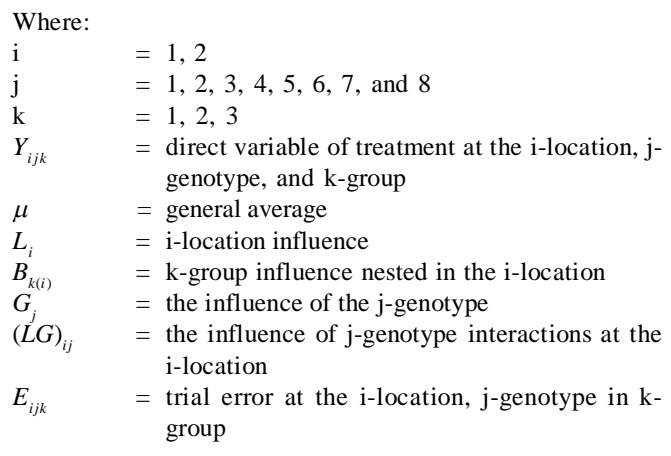

Variables that show significantly different results based on the analysis of the combined variety, then post hoc test were cup taste profile analyzed using the honestly significant difference (HSD) test method at $\alpha=5 \%$.

\section{Cup Taste Profile and Biochemical Compounds Correlation}

Organoleptic test results by the SCA method revealed that flavor data consists of eleven flavor variables : fragrance/aroma, flavor, aftertaste, acidity, body, balance, sweetness, clean cup, uniformity, overall and total score. Seven variables were analyzed using principal component analysis (PCA), while four others were not included in the analysis process. Of those four variables, three of them were qualitative variables (sweetness, uniformity, and cleancup), and the last one is the total score which is a function of the sum of the other nine variables.

According to Mattjik \& Sumertajaya (2011) the PCA is a linear combination of $\mathrm{p}$ origin variables, therefore

$$
\mathrm{Y}=\mathrm{A} \mathrm{X}
$$

Where:

$Y=\left[\begin{array}{c}Y_{1} \\ \ldots \\ Y_{p}\end{array}\right] A=\left[\begin{array}{ccc}a_{11} & \ldots & a_{1 p} \\ \ldots & \ldots & \ldots \\ a_{p 1} & \ldots & a_{p p}\end{array}\right] X=\left[\begin{array}{c}X_{1} \\ \ldots \\ X_{p}\end{array}\right]$

so the principle component (PC1) can be written as:

$$
\begin{aligned}
& Y_{1}=a_{11} X_{1}+a_{12} X+\ldots .+a_{1 p} X_{p} \\
& Y_{1}=a_{1} X
\end{aligned}
$$

Having a variety of: $S_{y z}^{2}=\operatorname{var}\left(a_{1} X\right)=a_{1} S a_{1}$

The selection of the vector coefficient of PC 1 is such way that the variance is 
the largest of others. To get this, it can be done through the Lagrange equation with constraint $=1$. For PC 2, it should be

$Y_{2}=a_{21} X_{1}+a_{22} X_{2}+\ldots+a_{2 p} X_{p}$

$Y_{2}=a_{1} X$

Having a variety of: $S_{y z}^{2}=\operatorname{var}\left(a_{2} X\right)=a_{2} S a_{2}$

The selection of the coefficient vector $a_{1} a_{1}$ is such way that the range $S_{y z}^{2}$ is maximum with constraints $a_{2} a_{2}=1$ and $\operatorname{Cov}(\mathrm{Y} 1, \mathrm{Y} 2)$ $=a_{1} S a_{2}=0$ or $a_{1} S a_{2}=0$. To achieve this, Lagrange equation can be applied.

Principle component analysis is carried out through the R X64 3.2.2 program, using the R-Commander graphic interface (GUI). $\mathrm{R}$-Commander is one of the RGUI with a simple display. It can be activated by installing the Rcmdr library in the $\mathrm{R}$ program (Tirta, 2005). Furthermore, to be able to perform PCA, the library used is FactoMineR and the graphical interface installed on the $\mathrm{R}$-Commander is the RcmdrPlugin and FactoMineR library. The FactoMineR library package is a multivariate data analysis package with an open source license (Lee et al., 2008).

Correlation between variables and PC values representing a variable group was done by principal component analysis (Husson et al., 2010). The analysis was performed through several stages: (1) calculating PC values representing variable groups, in this case, the observed variables were cup taste profile variable consisting of seven variable (fragrance/aroma, flavor, aftertaste, acidity, body, balance, sweetness, cleanup, overall and total score), (2) after obtaining PC that represents the cup taste profile variable, correlation analysis was carried out between the biochemical variable with the PC formed in stages 1, and (3) to facilitate the interpretation of results especially if the number of variables were observed too many, a biplot graph can be made between the correlation coefficients of each variable and the formed PC.

The correlation between biochemical quality variables and cup taste profile variable groups was analyzed using PCA contained in the FactoMineR package. Seven flavor variables (fragrance/aroma, flavor, aftertaste, acidity, body, balance, and overall) were selected as active variables, that was the main variable reduced to $\mathrm{PC}$, while the biochemical compound variables were selected as complementary variables. The analysis was carried out on each altitude growing locations and the combined data to determine the consistency of the correlations formed.

\section{RESULTS AND DISCUSSION}

\section{Biochemical Compounds}

The results of the combined analysis of variance on the trigonelline, sucrose, and caffeine compounds showed that the diversity was caused by the influence of interactions between genotypes $\times$ altitude, while the diversity of the content of chlorogenic acid compounds was caused by genotype influences (Table 2). This result is different from the study conducted by Getu et al. (2009) about multilocation experiments on 16 Arabica coffee genotypes in three locations at an altitude of more than 1,500 m asl. The results showed that there was no interaction of genotype $\times$ environment on caffeine, fat, trigonelline, sucrose, and chlorogenic acid. 
Performance of biochemical compounds and cup quality of Arabica coffee

Table 2. Result of combined analysis on variable biochemical content

\begin{tabular}{lccccc}
\hline Source of variation & $\mathrm{df}$ & Trigonelline & Chlorogenic acid & Sucrose & Caffeine \\
\hline Altitude & 1 & $* *$ & $\mathrm{~ns}$ & $* *$ & $* *$ \\
Block (Altitude) & 4 & $\mathrm{~ns}$ & $\mathrm{~ns}$ & $\mathrm{~ns}$ & $\mathrm{~ns}$ \\
Genotype & 7 & $* *$ & $\mathrm{~ns}$ & $* *$ & $* *$ \\
Genotype $\times$ Altitude & 7 & $* *$ & 2.62 & 4.60 & $* *$ \\
Coefficient variation $(\%)$ & 3.72 & 22.93 & & \\
\hline
\end{tabular}

Notes: df : degree of freedom; **: very significant different at $1 \%$ level; ns: non significant different.

\section{Trigonelline}

Trigonelline content in the high altitude had a higher average value than in the medium altitude. Genotype K29 was the genotype that had the highest content of trigonelline in all locations, followed by K99 and K34. BP700A was the genotype that had the lowest trigonelline content in all locations (Table 3 ). According to Guyot et al. (1996) altitude affects the trigonelline content, although the increase due to the addition of height is quite small. The results of this study indicated an increase in trigonelline content from the medium altitude to high altitude by $14 \%$. According to Sridevi \& Parvatam (2013), the trigonelline content of Robusta coffee is also positively correlated with altitude, the higher the planting location, the greater the trigonelline content.

\section{Chlorogenic Acid}

Based on the combined analysis of variance on the chlorogenic acid variable, the variance formed is caused by the influence of genotypes. The K8 genotype had the highest mean value of chlorogenic acid levels, while the K79 genotype had the lowest average value of chlorogenic acid (Table 4). These results strengthen the opinion of Guyot et al. (1996) that the altitude does not significantly affect the content of chlorogenic acid. The content of chlorogenic acid was more influenced by genotypes. Likewise, the results by Getu et al. (2009) and Kassaye et al. (2019) which revealed that the diversity in the variable chlorogenic acid content is more influenced by differences in genotype than differences in the growing environment. More detailed research on the effect of altitude on the content of chlorogenic acid was also carried out by Joet et al. (2010). The results showed that the formation of chlorogenic acid in seeds was not determined by the altitude but by the average daily temperature during seed formation. However, a study carried out by Sridevi \& Parvatam (2013) on Robusta coffee showed that the higher the location, the higher the content of chlorogenic acid.

\section{Sucrose}

The results of HSD test on the sucrose content showed that the higher the location, the higher the sucrose content of all genotypes. The mean value of sucrose content in the A1 was higher than in A2 with a mean increase of $235.6 \%$ (Table 5). The K99, $\mathrm{K} 79$, and $\mathrm{K} 8$ were genotypes that had the highest sucrose content in the A1, while in the A2, the K99 had the highest sucrose content. Genotype K29 was the genotype that had the lowest sucrose content in all locations.

Sucrose is an important precursor in the process of flavor forming. According to Ky et al. (2000), the higher the sucrose content, the better the flavor. The difference in sucrose content is strongly influenced by changes in environmental conditions because sucrose is a compound produced from photosynthesis (Huber, 1989). Sucrose is an indication of the 
Table 3. Trigonelline content (\%) of eight genotypes of Arabica coffee at two different altitude

\begin{tabular}{lcccccccccc}
\hline \multirow{2}{*}{ Altitude } & \multicolumn{10}{c}{ Genotype } \\
\cline { 2 - 11 } & BP700A & K8 & K29 & K34 & K79 & K99 & K130 & SIG \\
\hline High & $0.43 \mathrm{e}$ & $0.61 \mathrm{c}$ & $1.08 \mathrm{a}$ & $0.76 \mathrm{~b}$ & $0.45 \mathrm{de}$ & $0.96 \mathrm{a}$ & $0.58 \mathrm{~cd}$ & $0.50 \mathrm{~cd} \mathrm{e}$ & 0.672 \\
Medium & $0.40 \mathrm{t}$ & $0.56 \mathrm{~s}$ & $0.79 \mathrm{p}$ & $0.64 \mathrm{r}$ & $0.43 \mathrm{t}$ & $0.72 \mathrm{q}$ & $0.54 \mathrm{~s}$ & $0.46 \mathrm{t}$ & 0.574 \\
Mean & 0.422 & 0.583 & 0.939 & 0.704 & 0.442 & 0.837 & 0.561 & 0.482 & + \\
\hline
\end{tabular}

Notes: Values followed by the same letter(s) in the same row are not significantly different according to Honest Significant Different (HSD) at $\alpha=5 \% ;(+)=$ Interaction. SIG genotype at medium altitude was use two replication only. Value of MSD high altitude 0.1386 , MSD medium altitude $=0.0427$.

Table 4. Chlorogenic acid content (\%) of eight genotypes of Arabica coffee at two different altitude

\begin{tabular}{|c|c|c|c|c|c|c|c|c|c|}
\hline \multirow{2}{*}{ Altitude } & \multicolumn{8}{|c|}{ Genotype } & \multirow{2}{*}{ Mean } \\
\hline & BP700A & K8 & K29 & K34 & K79 & K99 & K130 & SIG & \\
\hline & \multicolumn{8}{|c|}{$\%$} & \\
\hline High & 6.194 & 7.853 & 8.289 & 5.406 & 6.072 & 5.879 & 6.471 & 6.740 & 6.613 \\
\hline Medium & 7.116 & 10.118 & 8.672 & 5.981 & 4.916 & 7.351 & 6.216 & 8.848 & 7.339 \\
\hline Mean & $6.65 \mathrm{ab}$ & $8.99 \mathrm{a}$ & $8.48 a b$ & $5.69 \mathrm{ab}$ & $5.49 \mathrm{~b}$ & $6.61 \mathrm{ab}$ & $6.34 \mathrm{ab}$ & $7.58 \mathrm{ab}$ & - \\
\hline
\end{tabular}

Table 5. Sucrose content $(\%)$ of eight genotypes of Arabica coffee at two different altitude

\begin{tabular}{|c|c|c|c|c|c|c|c|c|c|}
\hline \multirow{2}{*}{ Altitude } & \multicolumn{8}{|c|}{ Genotype } & \multirow{2}{*}{ Mean } \\
\hline & $\mathrm{BP} 700 \mathrm{~A}$ & K8 & K29 & K34 & K79 & K99 & K130 & SIG & \\
\hline & \multicolumn{8}{|c|}{$\%$} & \\
\hline High & $6.28 \mathrm{c}$ & $7.76 \mathrm{ab}$ & $4.77 \mathrm{~d}$ & $5.84 \mathrm{~cd}$ & $8.10 \mathrm{a}$ & $8.53 \mathrm{a}$ & $5.80 \mathrm{~cd}$ & $6.69 \mathrm{bc}$ & 6.722 \\
\hline Medium & $2.79 \mathrm{st}$ & $2.66 \mathrm{r}$ & $2.46 \mathrm{u}$ & $2.73 \mathrm{t}$ & $3.22 \mathrm{q}$ & $3.34 \mathrm{p}$ & $2.78 \mathrm{rs}$ & $2.82 \mathrm{r}$ & 2.853 \\
\hline Mean & 4.537 & 5.208 & 3.616 & 4.284 & 5.663 & 5.937 & 4.597 & 4.754 & + \\
\hline
\end{tabular}

Notes: Values followed by the same letter(s) in the same row are not significantly different according to Honest Significant Different (HSD) at $\alpha=5 \% ;(+)=$ Interaction. SIG genotype at medium altitude was use two replication only. Value of MSD high altitude 1.2203 , MSD medium altitude $=0.1393$.

level of coffee berries maturity and is greatly influenced by environmental conditions, especially altitude. The results of this study are in line with the research conducted by Worku et al. (2017) showing an increase in the content of sucrose due to the altitude of the planting site. A decrease in sucrose was caused by a decline in altitude from $1,400 \mathrm{~m}$ asl. to $1,100 \mathrm{~m}$ asl, which reached up to $10 \%$ (Guyot et al., 1996). The decrease in sucrose content from the A1 (1,250 m asl.) to the A2 (700 m asl.) was $135.6 \%$. This shows that changes in environmental conditions at an altitude of $700 \mathrm{~m}$ asl. causes a decrease in the physiological ability of coffee plants so that they can not produce and accumulate photosynthesis properly.

\section{Caffeine}

Based on the combined analysis of variance, the diversity of caffeine levels is caused by the effect of interactions between genotypes $\times$ altitude (Table 2). K8 was the genotype that had the highest caffeine content in the both altitudes. K130 genotype had the lowest caffeine content in both altitudes (Table 6). According to Farah et al. (2006), genetic variation has greater effect in controlling the caffeine content of seeds compared to environment and cultivation practices. These results was possible because caffeine is formed when the seeds are still young, then the formation of caffeine will decrease along with the age of seeds (Maluf et al., 2009; Perrois et al., 2015), so that 
Performance of biochemical compounds and cup quality of Arabica coffee

Table 6. Caffeine content $(\%)$ of eight genotypes of Arabica coffee at two different altitude

\begin{tabular}{|c|c|c|c|c|c|c|c|c|c|}
\hline \multirow{2}{*}{ Altitude } & \multicolumn{8}{|c|}{ Genotype } & \multirow{2}{*}{ Mean } \\
\hline & BP700A & K8 & K29 & K34 & K79 & K99 & K130 & SIG & \\
\hline & \multicolumn{8}{|c|}{$\%$} & \\
\hline High & $1.05 \mathrm{~b}$ & $1.24 \mathrm{a}$ & $1.04 \mathrm{bc}$ & 0.89 def & $0.85 \mathrm{ed}$ & 0.94 cde & $0.79 \mathrm{f}$ & $0.97 \mathrm{bcd}$ & 0.972 \\
\hline Medium & $0.67 \mathrm{qr}$ & $1.17 \mathrm{p}$ & $0.71 \mathrm{q}$ & $0.62 \mathrm{qr}$ & $0.60 \mathrm{qr}$ & $0.63 \mathrm{qr}$ & $0.58 \mathrm{r}$ & $0.64 \mathrm{qr}$ & 0.707 \\
\hline Mean & 0.863 & 1.204 & 0.879 & 0.757 & 0.725 & 0.784 & 0.686 & 0.841 & + \\
\hline
\end{tabular}

Notes: Values was followed by the same letter(s) in the same row are not significantly different according to Honest Significant Different (HSD) at $\alpha=5 \% ;(+)=$ Interaction. SIG genotype at medium altitude was use two replication only. . Value of MSD high altitude 0.1143 , MSD medium altitude $=0.1134$.

differences in fruit maturity due to the altitude differences does not cause differences in caffeine content.

Environmental conditions greatly affect the performance of biochemical compounds of Arabica coffee genotypes tested. The diversity formed in the test is mostly caused by environmental influences and followed by genotypes. The influence of genotype $x$ environment interaction on the quality characteristics of Arabica coffee will limit the development of Arabica coffee varieties that can adapt widely to various environmental conditions. Genotype $\times$ environment interactions can hinder the progress of selection, often interfere in the selection of superior varieties (Eberhart \& Russell, 1966), and complicate to make valid conclusions if a variety experiment is carried out in a wide range of environments Nasrullah (1981). Development of Arabica coffee should be carried out using locationspecific varieties so that the quality of coffee is acceptable by consumers. Conservation and enrichment of germplasm, evaluation, and mapping of the quality of superior genotypes in various environmental conditions must be done to obtain new varieties with a specific location.

\section{Cup Taste Quality}

The results of Principle components analysis of Arabica's seven variables flavor obtained seven eigenvalues. Determination of the amount of PC was based on the method of the minimum percentage value of diversity that can be explained, so it was selected PC1 (explaining $84.18 \%$ diversity of data) and PC2 (13.94\% diversity of data) (Table 7). The cumulative total diversity that could be explained by PC1 and PC2 of $98.1 \%$ was already high, so the values of PC1 and PC2 will be used for further analysis. According to Mattjik \& Sumertajaya (2011), there was no standard benchmark for the minimum percentage of diversity, but $70 \%$ was the minimum standard that is often used.

Based on the correlation value of each variable to the value of $\mathrm{PC}, \mathrm{PC} 1$ represents seven flavor variables (fragrance, flavor, aftertaste, acidity, balance, and overall) and PC2 represents one variable, that is the body (Table 8).

Biplot graphs formed from PC1 and PC2 divide the flavor of eight Arabica coffee genotypes into two groups, namely the genotype group planted in high altitude environment and the genotype group planted in medium altitude. Genotypes in high altitude are grouped into quadrants one and quadrants two with positive $\mathrm{PC} 1$ regions, while genotypes planted in medium altitude were in quadrants three and four with negative PC1 values (Figure 1). These conditions indicate that the cup taste of genotypes planted in high altitude has a high PC1 value (fragrance, flavor, aftertaste, acidity, balance, overall, and total score), whereas genotypes planted in medium altitude have low PC1 values. 
Table 7. Eigenvalue of cuptaste attribute

\begin{tabular}{lccc}
\hline PC & Eigenvalue & Percentage of variance $(\%)$ & Cumulative percentage of variance $(\%)$ \\
\hline 1 & 5.893 & 84.18 & 84.18 \\
2 & 0.976 & 13.94 & 98.12 \\
3 & 0.064 & 0.92 & 99.04 \\
4 & 0.043 & 0.60 & 99.64 \\
5 & 0.015 & 0.22 & 99.86 \\
6 & 0.007 & 0.09 & 99.96 \\
7 & 0.003 & 0.03 & 100 \\
\hline
\end{tabular}

Table 8. Correlation of cuptaste attribute to eigenvalue

\begin{tabular}{lcc}
\hline Variable & PC1 & PC2 \\
\hline Fragrance & 0.957 & -0.193 \\
Flavor & 0.995 & 0.003 \\
Aftertaste & 0.992 & 0.036 \\
Acidity & 0.981 & -0.084 \\
Body & 0.265 & 0.963 \\
Balance & 0.989 & 0.019 \\
Overall & 0.994 & -0.046 \\
\hline
\end{tabular}

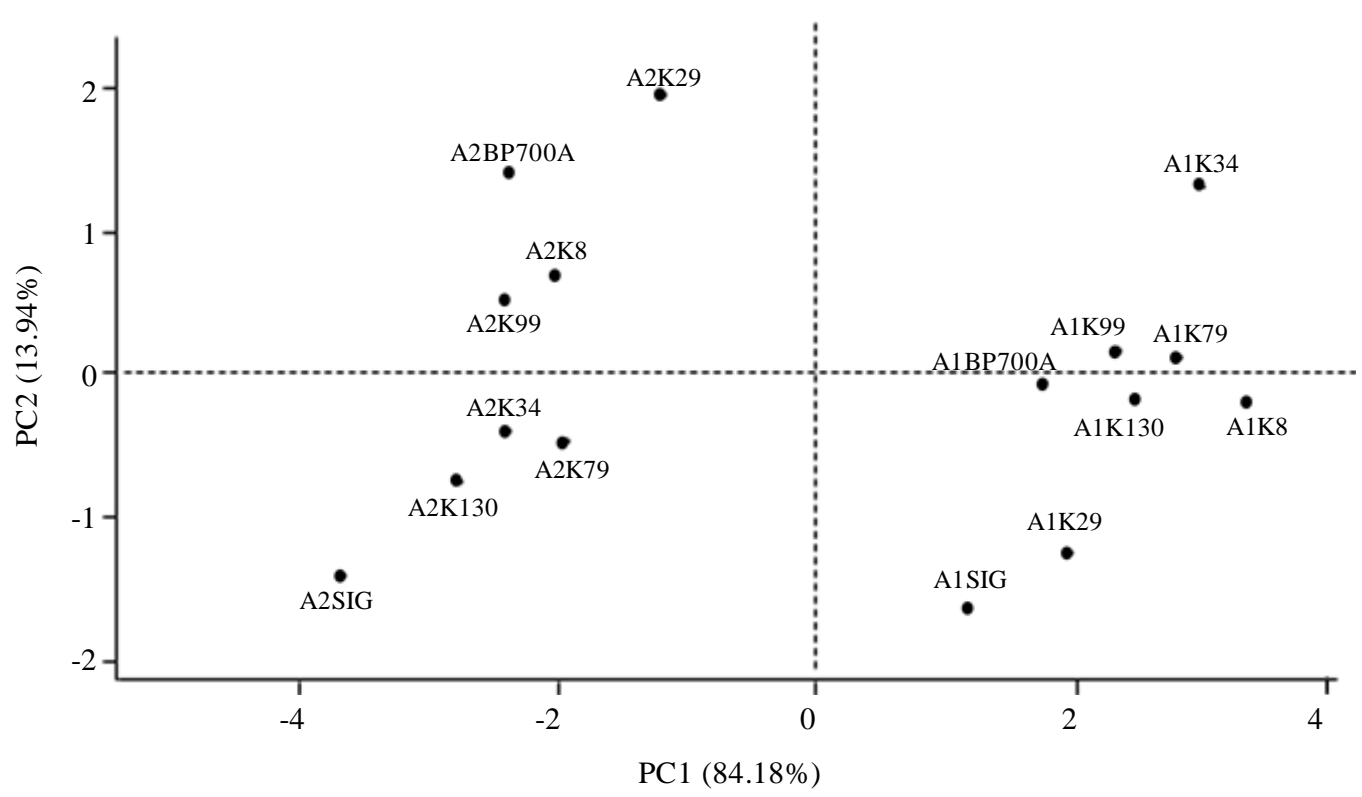

Figure 1. Biplot graph of principal component analysis of cuptaste attribute based on PC1 and PC2. (A1 = high altitude; $\mathrm{A} 2$ = medium altitude).

\section{Altitude Effect}

Principle component analysis on cup taste profile variable brought the genotypes into two groups: high altitude group and medium altitude genotype group. The results of this grouping indicate that the altitude has a very big influence on the quality of the coffee flavor. The characteristics of the flavor are also very different. Based on the panelist comments, the characteristics of genotypes planted in the high altitude are floral, spicy, fruity that point to lemons. The characteristics of Arabica grown in medium altitude tend to be herbs, green, and grassy. According to Decazy et al. (2003), Arabica grown at an altitude of lower than $850 \mathrm{~m}$ asl. tends to produce high bitterness, scented grassy, 
and astringent. Flavor profile in the high altitude environment has a much better value on the fragrance, flavor, aftertaste, acidity, balance, and overall (Figure 2). Flavors that do not change due to an altitude decrease is the body.

The altitude gives a big influence on the quality of the coffee (Bertrand et al., 2006; Lara-Estrada \& Vaast, 2006). Altitude will affect the daily temperature, generally, an increase in height of $100 \mathrm{~m}$ will reduce the average daily temperature by $0.6^{\circ} \mathrm{C}$ (Descroix $\&$ Wintgens, 2004). The temperature has an important role in the phenology cycle of coffee plants, especially in the phase of development and processing of coffee beans (Guyot et al., 1996). At lower temperatures, there is a delay in fruit ripening, so the fruit filling process becomes longer and more perfect (Vaast et al., 2006). Coffee planted in the high altitude also tends to have a leaf area : fruit ratio produced larger than in the lowlands. The higher the leaf area ratio : number of fruits will increase the supply of carbohydrates in the fruit (Vaast et al., 2005).

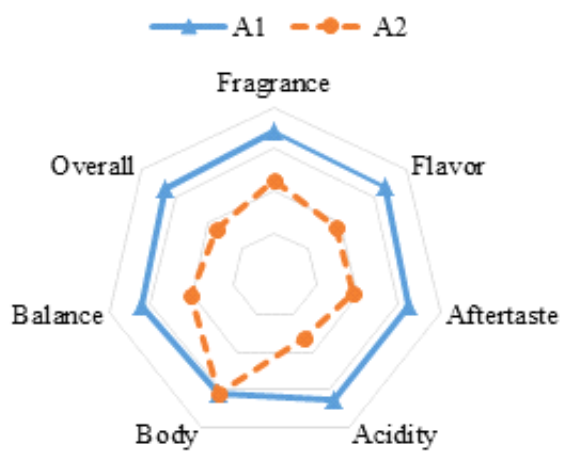

Figure 2. Cuptaste profile of tested genotypes at high altitude (A1) and medium altitude (A2).

Improving the quality of Arabica coffee in the medium altitude can be done with genetic improvement of plants. The utilization of modern varieties, such as hybrid varieties crossing between inter specific species with better adaptability to marginal environmental conditions, has been widely reported (Bertrand et al., 2006). Modern varieties was formed from the crossing between traditional Arabica varieties (pure line Arabica coffee) and offspring from the crossing of Arabica coffee with other coffee species such as Robusta (C. canephora) and Liberica coffee (C. liberica) (often referred to as introgressed variety). The main purpose of the crossing is to obtain resistance genes belonging to the species C. canephora or C. liberica. Initially, modern coffee varieties were less favored by consumers because the quality of the flavor was not as good as traditional varieties, but after undergoing the advanced selection process, many modern varieties with flavors not significantly different from traditional varieties were obtained (Bertrand et al., 2006; van der Vossen, 2009; Sobreira et al., 2015)

Modifying the conditions of the microclimate in the medium altitude to improve the cup quality of the coffee can be done through planting shade trees. It reduces the surface temperature of the soil and leaves, maintains the stability of daily temperature fluctuations around plants, however; it can inhibit plant vegetative growth and flowering induction which results in a decrease in plant productivity (Snoeck \& Lambot, 2004). Shade tree can reduce the productivity of coffee by $20 \%$, but it will protect the plant from production fluctuations due to the nature of the biennial bearing (Vaast et al., 2005). The decrease in productivity due to the shade will also be compensated by improvement the quality of Arabica because competition between fruits for nutrition will be reduced, increase the leaf area, number of fruit, and slow the ripening of the fruit for about one month (Vaast et al., 2006).

In addition by providing shade tree, the quality improvement of Arabica at the medium altitude can be done by intensive fertilization. Fertilization has a positive influence on coffee flavor in suboptimum-optimum land conditions 
(630-1,350 $\mathrm{m}$ asl.) (Lara-Estrada \& Vaast, 2006). Fertilization has a positive influence on the characteristics of seed size, seed weight, and reduces the formation of abnormal seeds. Fertilization also increases the accumulation of flavor precursor compounds, which will ultimately produce good quality coffee (Decazy et al., 2003; Franca et al., 2005). The combination of the use of location-specific varieties, the providing of shade, and the fertilizing can improve the quality of the Arabica coffee.

This research was conducted in different climatic conditions with different rainfall. The rainfall was not used as a single factor that could influence research results. The optimal rainfall interval for growing Arabica was $1,400-2,000 \mathrm{~mm}$ per year with a maximum of $3000 \mathrm{~mm}$ (Wintgens, 2004). Rainfall in high and medium altitudes are still within this interval so that it was still optimum for coffee growing. According to Silva et al. (2005), the amount of water (irrigation/rain) was not the main factor affecting the chemical content of the seeds. The main factor influencing the quality of coffee beans was the planting site, combining the influence of height, soil type, rainfall and other factors which shape the characteristics of the growing environment. A recent study on the effect of rainfall on the chemical content and the quality of coffee beans was conducted by Joet et al. (2015). The results of their study showed that there was no significant correlation between rainfall and the potential evapotranspiration on the quality components, among other lipids, chlorogenic acid, sugar, and caffeine. Therefore, rainfall was not discussed as a single factor that influences the results of this study. The results of the study was only influenced by the interaction of existing environmental factors, namely altitude, temperature, rainfall, soil type, and so on.

\section{Genotype Influence}

Principle Component 1 was the largest PC which explains $84.18 \%$ of the data diversity so that it can be used as the main reference in selecting genotypes with the best cup quality (Table 7). Biplot graphs from PC1 and PC2 showed that the K8 was the genotype that had the best taste in the highlands, followed by genotypes K34 and K79 (Figure 1). The position of the $\mathrm{K} 8$ genotype in the $\mathrm{x}$-axis was the far right so it had the highest PC1 value, meaning that $\mathrm{K} 8$ was the genotype which had the best fragrance, flavor, aftertaste, acidity, body, balance, and overall. The results were also shown by the highest $\mathrm{K} 8$ total score (84.31) compared to other genotypes (Figure 3). The genotype that had the lowest taste in the high altitude was Sigararutang with a total score of 82.47 .

Quadrant three and quadrant four showed that the K29 was the genotype which had the best flavor in the medium altitude (Figure 1, Figure 3), while Sigararutang had the lowest value (78.08).

$\mathrm{K} 34, \mathrm{~K} 79$, and $\mathrm{K} 8$ are the genotypes that have the best flavor in high altitude, but in medium altitude, the flavor performance decreased, with lower values than K29 genotype. In contrast, the K29 genotype had the best flavor in medium altitude, but in high altitude, the flavor performance was lower than K34, K79, and K8. These conditions indicate that there was an interaction between the genotype $\times$ altitude growing location. A study conducted by Gichimu et al. (2012) on 34 families of 'Ruiru 11' variety in three locations showed an interaction of genotype $x$ environment in seven flavor variables (fragrance, flavor, aftertaste, acidity, balance, preference, and total score), whereas in the body, there is no interaction between genotype $\times$ environment. 


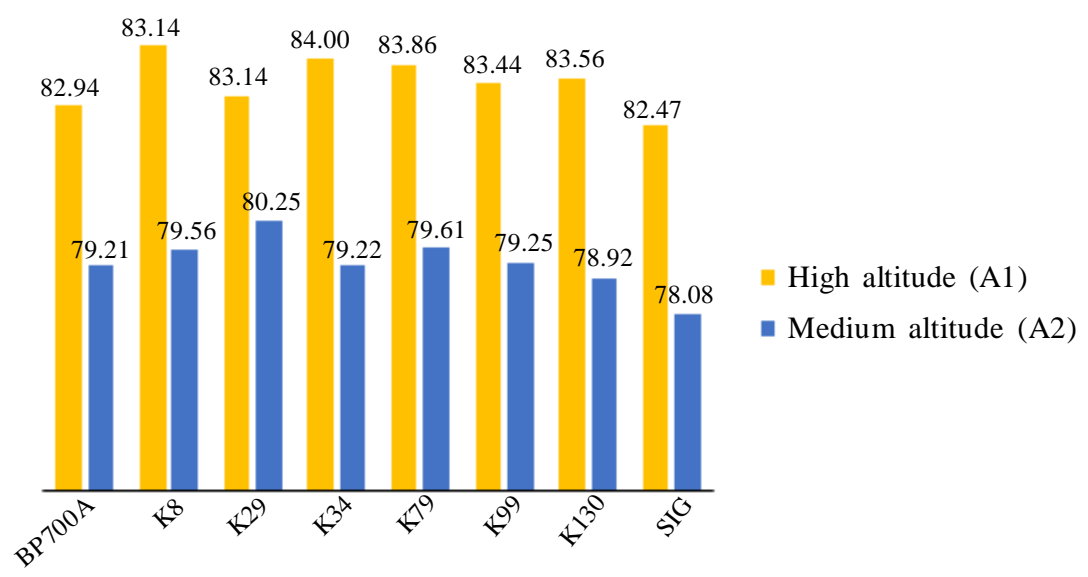

Figure 3. Total score of tested genotypes at high altitude and medium altitude

Another result has been proposed by Bertrand et al.(2006), which states that at an altitude of more than 1,200 $\mathrm{m}$ above sea level, differences in genotypes do not have a real influence on the flavors, but in the medium altitude (700-900 $\mathrm{m}$ above sea level) differences in genotypes give a real influence on flavor produced. The cause was that in the high altitude, limiting factors for plant growth (intensity of pests and diseases, fluctuations in temperature) that can inhibit the process of formation of a good taste was relatively smaller. Almost all genotypes can grow well in the highlands and produce well-developed coffee beans that produce the same high flavor value. The difference only occurs in the specific characteristics of the flavor, such as floral scents are found in Sumatra Arabica coffee, bright acidity in Kalosi Arabica coffee, and spicy in java coffee. In the medium altitude ground environmental conditions, the potential for flavor is strongly influenced by the factor of adaptability and the ability of genotypes to grow and develop in marginal environmental conditions. Therefore, the selection of specific location superior genotypes with adaptability in the medium altitude is very important.

The Sigararutang (SIG) genotype was consistently lower in term of compared to other genotypes, both in the highland and the medium altitude. Sigararutang is a variety of participatory breeding results from North Sumatra that has good adaptability to the high altitude environments with wet climate types. The results of the Principal Component Analysis show that the Sigararutang variety is relatively unfavorable when planted at a high altitude with a dry climate type and is not suitable when planted at a medium altitude.

\section{Biochemical Compounds and Coffee Flavor Correlation}

The results of the PCA on the flavor variables at the highlands obtained two PC which explained $77.17 \%$ of diversity (Table 9). Principle component 1 correlates with flavor, aftertaste, acidity, balance and overall flavor variables, while PC 2 correlates with fragrance and body (Table 10).

Principle Components Analysis on flavor variable at the medium altitude obtained two PC which explained $86.13 \%$ of the diversity. Principle component 1 explains the diversity of flavors, aftertaste, acidity, body, balance, and overall, while PC2 explains the diversity of fragrance (Table 11). 
Table 9. Eigenvalue of coorelation matrix on cup taste profile at high altitude (A1)

\begin{tabular}{lccc}
\hline PC & Eigenvalue & Percentage of diversity (\%) & Cummulative percentage of diversity (\%) \\
\hline 1 & 4.27 & 61.05 & 61.05 \\
2 & 1.12 & 16.11 & 77.17 \\
3 & 0.91 & 13.02 & 90.19 \\
4 & 0.29 & 4.21 & 94.40 \\
5 & 0.19 & 2.78 & 97.18 \\
6 & 0.11 & 1.60 & 98.79 \\
7 & 0.08 & 1.20 & 100 \\
\hline
\end{tabular}

Table 10. Correlation value of cup taste profile attribute to $\mathrm{PC} 1$ and $\mathrm{PC} 2$ at high altitude (A1)

\begin{tabular}{lcc}
\hline Attribute/Variable & PC1 & PC2 \\
\hline Fragrance & 0.18 & $0.87 * *$ \\
Flavor & $0.93 * *$ & 0.01 \\
Aftertaste & $0.92 * *$ & -0.05 \\
Acidity & $0.81 * *$ & -0.34 \\
Body & 0.36 & $0.46 * *$ \\
Balance & $0.92 * *$ & 0.11 \\
Overall & $0.93 * *$ & -0.13 \\
\hline Trigonelline & 0.099 & -0.08 \\
Chlorogenic acid & 0.069 & -0.02 \\
Sucrosa acid & 0.150 & 0.08 \\
Caffeine & 0.082 & -0.05 \\
\hline
\end{tabular}

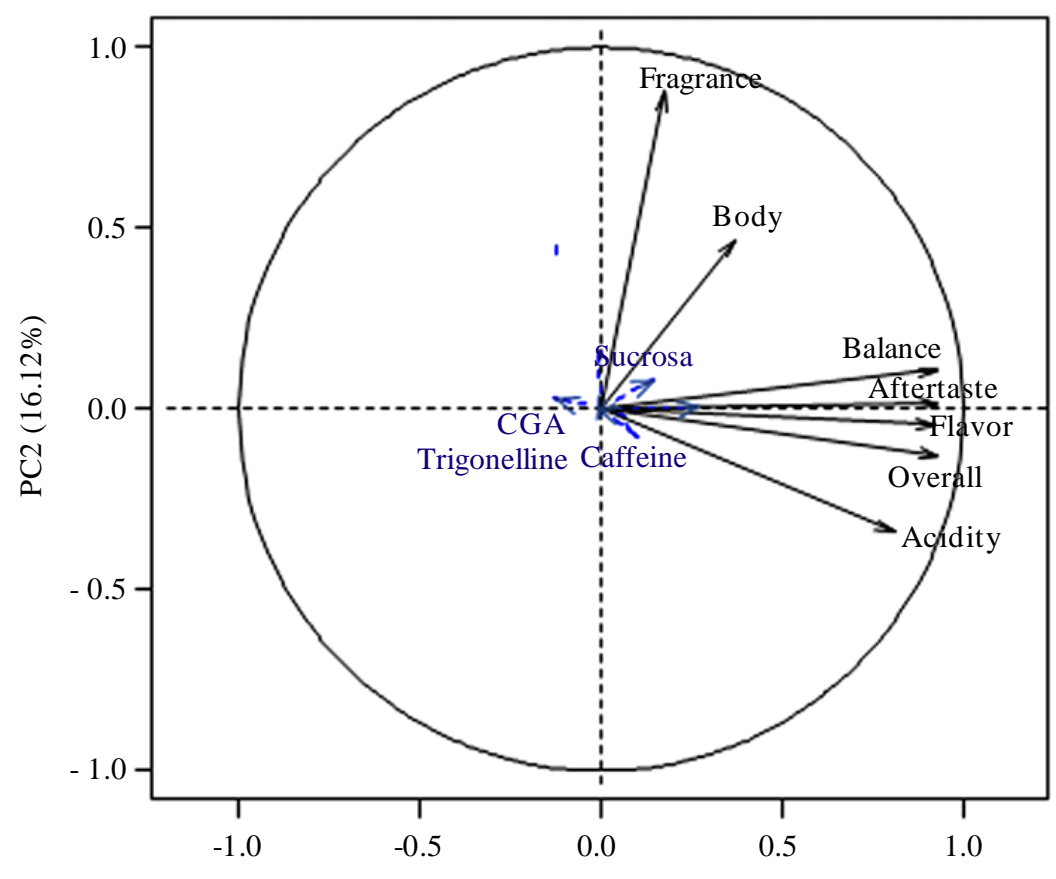

PC1 $(61.05 \%)$

Figure 4. Principle component analysis on cup taste profile attribute and correlation between its variables with biochemical content at high altitude (A1) 
Principle component 1 (fragrance) did not have correlation with cup taste variable, whereas PC2 correlated with sucrose content although the correlation value was not significantly different (Figure 5) (Table 12).
Separate Principle Components Analysis can be used to determine the effect of genotypes on the flavor. Comparison of the results of the PCA between the high altitude and medium altitude shows that there are differences

Table 11. Eigenvalue of correlation matrix on cup taste profile at medium altitude (A2)

\begin{tabular}{lccc}
\hline PC & Eigenvalue & Percentage of diversity (\%) & Cummulative percentage of diversity $(\%)$ \\
\hline 1 & 5.05 & 72.19 & 72.19 \\
2 & 0.97 & 13.94 & 86.13 \\
3 & 0.48 & 6.88 & 93.01 \\
4 & 0.19 & 2.81 & 95.82 \\
5 & 0.15 & 2.12 & 97.93 \\
6 & 0.10 & 1.45 & 99.38 \\
7 & 0.04 & 0.62 & 100 \\
\hline
\end{tabular}

Table 12. Correlation value of cup taste profile attribute to PC1 and PC2 at medium altitude (A2)

\begin{tabular}{lcc}
\hline Attribute/Variable & PC1 & PC2 \\
\hline Fragrance & 0.34 & $0.94 * *$ \\
Flavor & $0.94 * *$ & -0.10 \\
Aftertaste & $0.89 * *$ & -0.26 \\
Acidity & $0.93 * *$ & 0.08 \\
Body & $0.78 * *$ & -0.01 \\
Balance & $0.93 * *$ & -0.10 \\
Overall & $0.95 * *$ & 0.04 \\
Trigonelline & 0.22 & -0.02 \\
Chlorogenic acid & -0.07 & 0.003 \\
Sucrose & -0.09 & -0.27 \\
Caffeine & 0.14 & -0.13 \\
\hline
\end{tabular}

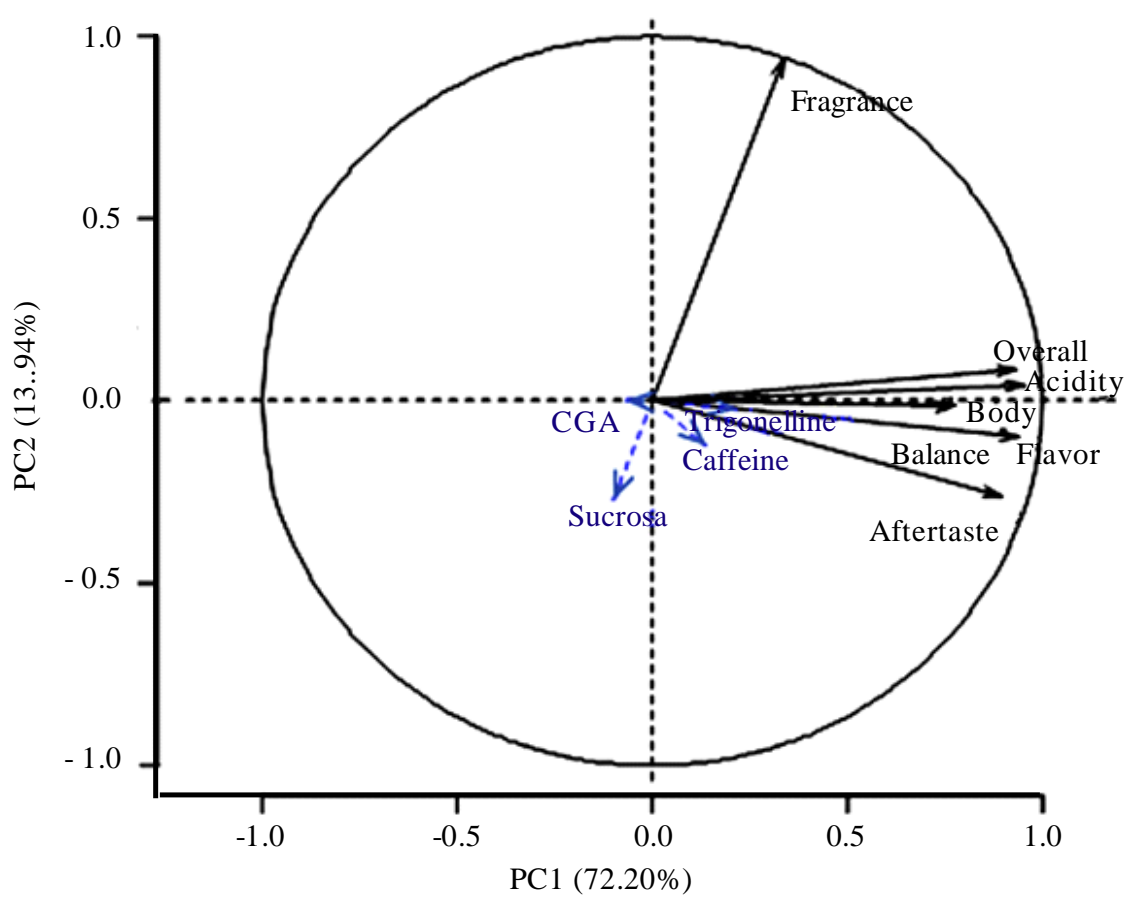

Figure 5. Principle component analysis on cup taste profile and its correlation with biochemical compound at medium altitude (A2) 
in the magnitude of the values of PC1 and $\mathrm{PC} 2$ and the composition of the variables that make up them. The amount of diversity that can be explained by $\mathrm{PC} 1$ and $\mathrm{PC} 2$ in the medium altitudes is $83.13 \%$ higher than the highlands (77.17\%). These results indicate that at the medium altitudes, the differences in genotype will produce a greater diversity of flavors than the diversity of flavors at highlands. Genotype $\times$ altitude interactions also cause inconsistencies in the value of the correlation between cup taste profile variables with biochemical quality components.

Result of PCA using combined data (high altitude and medium altitude) obtained two PC, which explained $93.42 \%$ diversity of flavor data (Table 13). Principle Component 1 represents the fragrance, flavor, aftertaste, acidity, balance, and overall variables, while PC2 describes the body variable (Table 14). Principle Component 1 had a real and positive correlation with sucrose and caffeine content (Figure 6).
The difference in the results of the PCA of the flavor and its correlation with the content of biochemical compounds showed that the environment had a significant effect on the quality attribute of Arabica coffee. The difference also showed that the genotypes tested changed in quality if planted at medium altitude. A strong correlation between flavor quality variables with biochemical compounds (sucrose, caffeine) is caused by environmental differences. This result can be demonstrated by conducting a partial correlation test on the variables that show a real correlation based on the PCA. The results of the partial correlation test by ignoring the influence of the environment showed that the correlation values were not significantly different (Appendix 1). Altitude had a strong influence on the formation of correlations among the observed variables. The second thing, panelists could not differentiate flavor differences due to the low variance value of a variables in one location. For example, the sucrose variable in high altitude had a

Tabel 13. Eigenvalue of correlation matrix on cup taste profile in high altitude (A1) and medium altitude A2)

\begin{tabular}{lccc}
\hline PC & Eigenvalue & Percentage of diversity (\%) & Cummulative percentage of diversity (\%) \\
\hline 1 & 5.60 & 80.07 & 80.07 \\
2 & 0.93 & 13.35 & 93.42 \\
3 & 0.29 & 4.22 & 97.64 \\
4 & 0.06 & 0.91 & 98.56 \\
5 & 0.05 & 0.67 & 99.23 \\
6 & 0.03 & 0.41 & 99.64 \\
7 & 0.02 & 0.36 & 100 \\
\hline
\end{tabular}

Table 14. Correlation value of cup taste profile attribute to PC1 and PC2 at high altitude (A1) and medium altitude (A2)

\begin{tabular}{lcc}
\hline Attribute/Variable & PC1 & PC2 \\
\hline Fragrance & $0.85 * *$ & -0.20 \\
Flavor & $0.98 * *$ & -0.01 \\
Aftertaste & $0.97 * *$ & -0.07 \\
Acidity & $0.97 * *$ & -0.01 \\
Body & $0.32 * *$ & $0.94 * *$ \\
Balance & $0.98 * *$ & 0.00 \\
Overall & $0.98 * *$ & -0.04 \\
Trigonelline & 0.26 & 0.01 \\
Chlorogenic acid & -0.19 & 0.23 \\
Sucrose & $0.81 * *$ & -0.25 \\
Caffeine & $0.59 * *$ & -0.15 \\
\hline
\end{tabular}




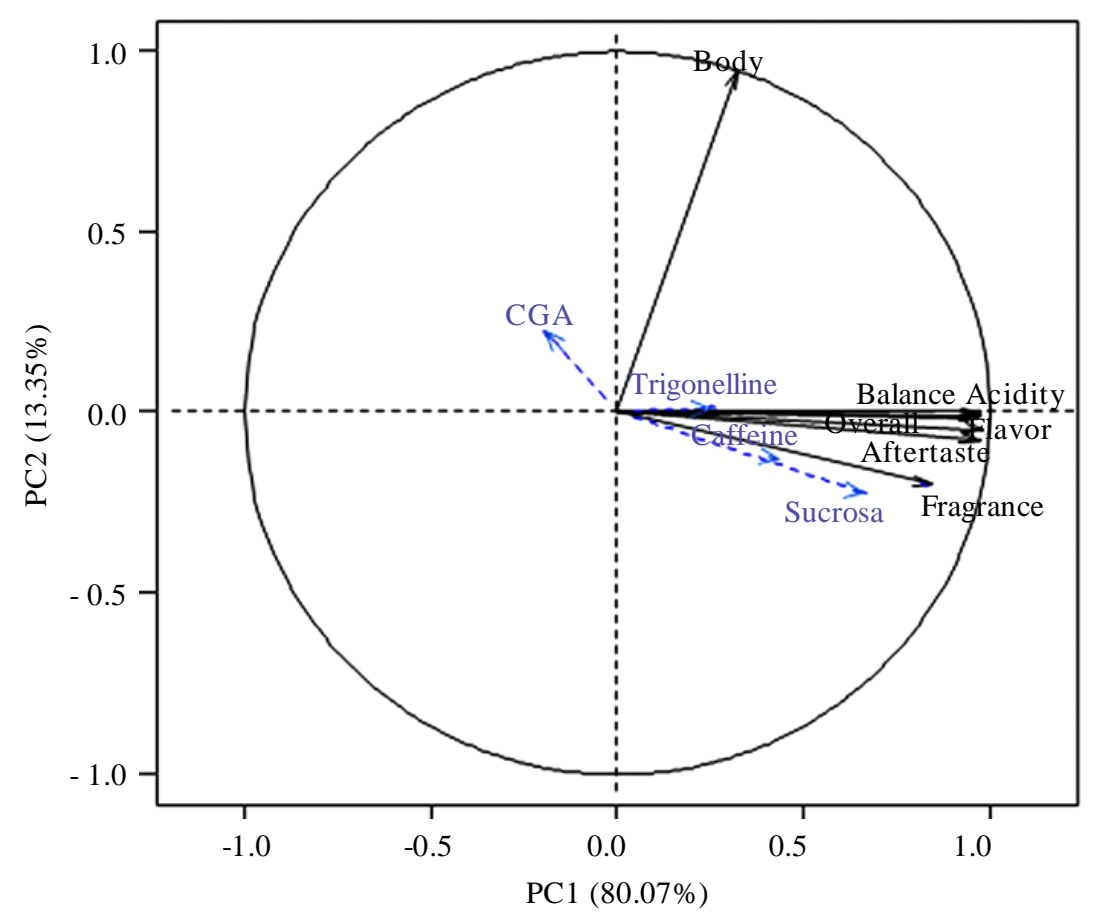

Figure 6. Principle component analysis on cup taste profile and its correlations with biochemical compound at high altitude (A1) and medium altitude (A2)

variance 1.655 ; while in medium altitude 0.135 ; and the combined variance of the two locations was 4.718. Test panelists were able to differentiate the differences in the combined flavor between high altitude and medium altitude which had a high variance, but were not able to properly differentiate the differences between genotypes in one location along and the decrease in variance values in each location.

A study conducted by Avelino et al. (2005) also showed that the observed biochemical compounds (sucrose, caffeine, chlorogenic acid, and trigonelline) could not explain the profile of flavors, so it is necessary to observe other biochemical compounds such as amino acids, peptides, and proteins. The correlation between biochemical variables and coffee flavor in different genotypes can also indicate a different relationship (Guyot et al., 1996). According to Guyot et al. (1996), the Bourbon varieties planted at different altitude showed no correlation between the biochemical compounds analyzed by the flavor variables, whereas, in the Catuai variety, there was a correlation between sucrose content and acidity variables. Different genotype has a different response to differences in the altitute of the planting site.

A study carried out by Farah et al. (2006) showed that the content of trigonelline, caffeine, and 3,4-dicaffeoilquinic acid revealed a positive correlation with good quality coffee. The organoleptic test model used by Farah et al. (2006) was a scoring method by classifying coffee quality in five categories: soft (good flavor and sweetness), hard (flavor with a little astringent and sweetness), rioysh (a bit of iodine smell), rio (unpleasant taste), and rio zona (flavors and aromas cannot be tolerated/consumed), so there are only five flavor variables observed 
by panelists. The number of observational variables that are not too much can increase the sensitivity and accuracy of the panelists in the assessment of coffee flavors. Following this matter, further flavor testing can be done by reducing the number of observed variables.

Determination of the number of variables was done based on the results of the PCA, that were the flavor variables which show low correlation with other variables were still observed, while the variables that had a strong correlation with other variables were selected one or two of the most important variables. In the high altitude environment conditions, fragrance and body are variables that did not correlate with other flavor variables, whereas in the medium altitude, the body is the only variable that does not correlate with other variables. Flavor, aftertaste, acidity, balance, and overall variables were consistent variables that have a strong correlation in all environmental conditions. The strong correlation between five variables showed that observations could be simplified by representing only the most important variables. According to Cantergiani et al. (1999) and Clarke (1987), flavor is the most important cup taste variable that must be tested in evaluating coffee quality, also it is the component that gets the highest preference in consumer ratings. Based on this matter, the flavor testing that requires good accuracy and differentiation, there are four flavor variables that need to be observed: fragrance/ aroma, flavor, body, and acidity.

Further observation needs to be done to determine the physical, biochemical, and flavor quality stability. The effect of repetition on the biochemical content variable was not significantly different so that in the future studies, a complete randomized design could be used by increasing the number of sample observations to improve the accuracy of the study. It is necessary to observe the correlation between flavor changes with morphological characteristics and other biochemical contents such as leaf area index, leaf area ratio, number of fruits, the period between pollination to harvested fruits, fat content, total protein, and amino acids.

Further research needs to be done to determine changes in plant metabolism due to differences in genotypes and planting site and their relationship with the quality of flavor using transcriptomic and metabolomic approaches.

\section{CONCLUSIONS}

Altitude has a significant effect on caffeine, sucrose, and trigonelline compounds. The effect of genotype $\times$ altitude interaction occurs on the content of caffeine compounds, trigonelline, and sucrose. Diversity in chlorogenic acid compounds was caused by genotype factors. Genotypes planted at high altitude have a better taste than genotypes at medium altitudes. The flavor components that change due to the decrease in altitude growing location were fragrance/aroma, flavor, aftertaste, acidity, balance, and overall, while the flavor component that does not change was the body. Special characters of coffee aroma at high altitude were floral, spicy, and fruity, while the aroma of the medium altitude were herbal, green and grassy. The genotype that has the best flavor at high altitude was K8 genotype, while the genotype with the best flavor at medium altitudes was the K29 genotype. There was a change in the pattern of correlation between the content of biochemical compound and flavor variable between high altitude and medium altitude. Altitude gives a greater influence on the formation of coffee flavors compared to the influence of genotypes. 


\section{ACKNOWLEDGEMENT}

The authors would like to acknowledge Dr. Retno Hulupi, Dr. Suyadi Mw, Wilys Samsul Arifin, Panelists Kalibendo plantation and KP. Andungsari for the fruitful discussions that they contributed to.

\section{REFERENCES}

Anonim (2014a). Ekspor Kopi Menurut Negara Tujuan. Badan Pusat Statistik.

Anonim (2014b). Kopi Berkelanjutan. Direktorat Jenderal Perkebunan Kementerian Pertanian. Jakarta.

Avelino, J.; B. Barboza; J.C. Araya; C. Fonseca; F. Davrieux; B. Guyot \& C. Cilas (2005). Effects of slope exposure, altitude and yield on coffee quality in two altitude terroirs of Costa Rica, Orosi and Santa Maria de Dota. Journal of the Science of Food and Agriculture, 85, 1869-1876.

Bertrand, B.; P. Vaast; E. Alpizar; H. Etienne; F. Davrieux \& P. Charmetant (2006). Comparison of bean biochemical composition and beverage quality of Arabica hybrids involving SudaneseEthiopian origins with traditional varieties at various elevations in Central America. Tree Physiology, 26, 1239-1248.

Cantergiani, E.; H. Brevard; R. Amado; Y. Krebs; A. Feria-Morales \& C. Yeretzian (1999). Characterisation of mouldy/earthy defect in green Mexican coffee. COLLOQUE Scientifique International sur le Café, 18. Helsinki (Finlandia), Agosto 2-6, 1999.

Clarke, R.J. (1987). Grading, storage, pre-treatments and blending. In: R.J. Clarke \& R. Macrae (Eds.), Coffee: Technology. Elsevier Science Publishers LTD, 321.

Clifford, M.N. (1985). Chemical and physical aspects of green coffee and coffee products. p. 305-374. In: Coffee: Botany, Biochemistry and Production of Beans and Beverage. Springer US, Boston, MA.
Dart, S.K. \& H.E. Nursten (1985). Volatile components. p. 223-265. In: Coffee. Springer Netherlands, Dordrecht.

Decazy, F.; J. Avelino; B. Guyot; J.J. Perriot; C. Pineda \& C. Cilas (2003). Quality of different Honduran coffees in relation to several environments. Journal of Food Science, 68, 2356-2361.

Demissie, M.; G. Taye \& M. Kebede (2011). Additive main effects and multiplicative interaction analysis of coffee germplasms from southern Ethiopia. SINET: Ethiopian Journal of Science, 34, 63-70.

Descroix, F. \& J.N. Wintgens (2004). Establishing a coffee plantation. In: J.N. Wintgens (Ed.), Coffee: Growing, Processing, Sustainable Production. WILEY-VCH Verlag $\mathrm{GmbH} \& \mathrm{Co}$. KGaA, Weinheim.

Eberhart, S.A. \& W.A. Russell (1966). Stability parameters for comparing varieties 1 . Crop Science, 6, 36.

Farah, A. \& C.M. Donangelo (2006). Phenolic compounds in coffee. Brazilian Journal of Plant Physiology, 18, 23-36.

Farah, A.; M.C. Monteiro; V. Calado; A.S. Franca \& L.C. Trugo (2006). Correlation between cup quality and chemical attributes of Brazilian coffee. Food Chemistry, 98, 373-380.

Flamen, I. (1989). Coffee, cocoa, and tea. Food Reviews International, 5, 317-414.

Franca, A.S.; J.C.F. Mendonça \& S.D. Oliveira (2005). Composition of green and roasted coffees of different cup qualities. LWT - Food Science and Technology, 38, 709-715.

Getu, B.; B. Bayetta; Z. Habtamu; J.P. Labouisse; F. Davrieux \& B. Bertrand (2009). Stability of sensorial and biochemical traits of different geographical origin Ethiopian Arabica coffee (Coffea arabica L.) accessions under three contrasting environmental conditions. $22^{\text {nd }}$ International Conference on Coffee 
Science, ASIC 2008, Campinas, SP, Brazil, 14-19 September, 2008. 604-607.

Gichimu, B.M.; E.K. Gichuru; G.E. Mamati \& A.B. Nyende (2012). Selection within Coffea arabica cv. Ruiru 11 for high cup quality. African Journal of Food Science, 6, 456-464.

Guyot, B.; D. Gueule; J.C. Manez; J.J. Perriot; J. Giron \& L. Villain (1996). Influence de l'altitude et de l'ombrage sur la qualité des cafés Arabica. Plant Rech. Dévelop, 3, 272-283.

Huber, S.C. (1989). Biochemical mechanism for regulation of sucrose accumulation in leaves during photosynthesis. Plant Physiol, 80, 545-551.

Hulupi, R. (2006). Kajian Genetika Ketahanan Kopi Arabika Terhadap Nematoda Penggali Akar (Radopholus similis Cobb). Ph.D Disertation, Universitas Gadjah Mada. Yogyakarta.

Husson, F.; S. Le \& J. Pages (2010). Exploratory Multivariate Analysis by Example Using R. In: Chapman \& Hall/CRC Computer Science \& Data Analysis. Taylor \& Francis.

Joët, T.; A. Laffargue; F. Descroix; S. Doulbeau; B. Bertrand; A. de Kochko \& S. Dussert (2010). Influence of environmental factors, wet processing and their interactions on the biochemical composition of green Arabica coffee beans. Food Chemistry, 118, 693-701.

Joët, T.; B. Bertrand \& S. Dussert (2015). Environmental effects on coffee seed biochemical composition and quality attributes: a genomic perspective. Proceedings of the $25^{\text {th }}$ International Conference on Coffee Science. ASIC. Paris: ASIC. 42-49.

Kassaye, T.; A. Desalegn; B. Derbew \& B. Pascal (2016). Biochemical composition of Ethiopian coffees (Coffea arabica L.) as influenced by variety and postharvest processing methods. African Journal of Food Science, 13, 48-56.
Ky, C.L.; S. Doulbeau; B. Guyot; S. Akaffou; A. Charrier; S. Hamono; J. Louarn \& M. Noirot (2000). Inheritance of coffee bean sucrose content in the interspecific cross Coffea pseudozanguebariae $\times$ Coffea liberica "dewevrei." Plant Breeding, 119, 165-168.

Lara-Estrada, L. \& P. Vaast (2006). Effects of altitude, shade, yield and fertilization on coffee quality (Coffea arabica L. var. Caturra) produced in agroforestry systems of the Northern Central Zones of Nicaragua. Journal of Food Science, 68, 2356-2361.

Lee, S.; J. Josse \& F. Husson (2008). FactoMineR: an R Package for multivariate analysis. Journal of Statistical Software, 25, 1-18.

Leloup, V.; A. Louvrier \& R. Liardon (1995). Degradation mechanisms of chlorogenic acids during roasting. $16^{\text {th }}$ International Conference on Coffee Science (ASIC). Kyoto, Japan.

Leroy, T.; F. Ribeyre; B. Bertrand; P. Charmetant; M. Dufour; C. Montagnon; P. Maraccini \& D. Pot (2006). Genetics of coffee quality. Brazilian Journal of Plant Physiology, 18, 229-242.

Lingle, T.R. (1986a). The Coffee cupper's Handbook: A Systematic Guide to the Sensory Evalution of Coffee's Flavor. Coffee Development Group, Washington D.C.

Lingle, T.R. (1986b). The Basic of Cupping Coffee. Coffee Development Group, Washington D.C.

Maluf, M.P.; C.C. da Silva; M. de P.A. de Oliveira; A.G. Tavares; M.B. Silvarolla \& O. Guerreiro Filho (2009). Altered expression of the caffeine synthase gene in a naturally caffeine-free mutant of Coffea arabica. Genetics and Molecular Biology 32, 802-810.

Mattjik, A.A. \& I.M. Sumertajaya (2011). Sidik Peubah Ganda dengan Menggunakan SAS. IPB PRESS, 423p.

Montavon, P.; E. Duruz; G. Rumo \& G. Pratz (2003). Evolution of green coffee protein profiles 
with maturation and relationship to coffee cup quality. Journal of Agricultural and Food Chemistry, 51, 2328-2334.

Nascimento, E.A.; S.A.L. Morais; R. Chang; F.J.T. Aquino; B.H.P. Alves \& R.J.C.F. Afonso (2015). Looking for unknown molecules in Arabica and Robusta coffee brews by high performance liquid chromatography coupled to high resolution mass spectrometry and differentiating both coffee species by this technique. International Journal of Applied, 5, 26-37.

Nasrullah (1981). A modified procedure for identifying varietal stability. Agricultural Science, 3, 153-159.

Neter, J.; M.H. Kutner; C.J. Nachtsheim \& W. Wasserman (1996). Applied linear statistical models. Regression. Analysis of Variance and Experimental Designs. Vol. 4. Irwin Chicago.

Perrois, C.; S.R. Strickler; G. Mathieu; M. Lepelley; L. Bedon; S. Michaux; J. Hussun; L. Mueller \& I. Privat (2015). Differential regulation of caffeine metabolism in Coffea arabica (Arabica) and Coffea canephora (Robusta). Planta, 241, 179-191.

Schmidt, F.H. \& J.H.A. Ferguson. (1951). Rainfall types based on wet and dry period ratios for Indonesia with Western New Guinea. Verhandelingen No. 52. Kementerian Perhubungan Djawatan Meteorologi dan Geofisika, Jakarta, 77p, Jakarta. .

Shibamoto, T. (1991). An overview of coffee aroma and flavor chemistry. ASIC, Proceedings of the $14^{\text {th }}$ international scientific colloquium on coffee.

Silva, E.A. da; P. Mazzafera; O. Brunini; E. Sakai; F.B. Arruda; L.H.C. Mattoso; C.R.L. Carralho \& R.C.M. Pires (2005). The influence of water management and environmental conditions on the chemical composition and beverage quality of coffee beans. Brazilian Journal of Plant Physiology, 17, 229-238.
Snoeck, J. \& C. Lambot (2004). Crop Maintenance. p. 976. In: Wintgens, J.N. (Ed.), Coffee: Growing, Processing, Sustuinable Production. WILEY-VCH Verlag $\mathrm{GmbH}$ \& Co. KGaA, Weinheim.

Sobreira, F.M.; A.C.B. de Oliveira; A.A. Pereira \& N.S. Sakyiama (2015). Potential of Híbrido de Timor germplasm and its derived progenies for coffee quality improvement. Australian Journal of Crop Science, 9, 289-295.

Sridevi, V. \& G. Parvatam (2013). Influence of altitude variation on trigonelline content during ontogeny of coffea canephora fruit. Journal of Food Studies, 2, 62-74.

Tirta, I.M. (2005). Panduan Program Statistika. UPT Penerbitan Universitas Jember.

Tolessa, K.; J. Dheer; L. Duchatean \& P. Boeckx (2016). Influence of growing altitude, shade and harvest period on quality andbio-chemical composition of Ethopian specialty coffee. Journal of the Science of Food and Agriculture, 97, 2849-2857.

Vaast, P.; B. Bertrand; J.J. Perriot; B. Guyot \& M. Génard (2006). Fruit thinning and shade improve bean characteristics and beverage quality of coffee (Coffea arabica L.) under optimal conditions. Journal of the Science of Food and Agriculture, 86, 197-204.

Vaast, P.; R. van Kanten; P. Siles; B. Dzib; N. Franck; J.M. Harmand \& M. Genard (2005). Shade: a key factor for coffee sustainability and quality. ASIC 2004. 20th International Conference on Coffee Science, Bangalore, India, 11-15 October 2004. Association Scientifique Internationale $d u$ Café (ASIC). p. 887-896.

van der Vossen, H.A.M. (2001). Agronomy I: Coffee breeding practices. p.184-201. In: R.J. Clarke \& O.G. Vitzthum (Eds.), Coffee: Recent Developments. Blackwell Science, Oxford, Great Britain.

van der Vossen, H.A.M. (2009). The cup quality of disease-resistant cultivars of Arabica coffee (Coffea arabica). Experimental Agriculture, 45, 323-332. 
Wamatu, J.N.; E. Thomas \& H.P. Piepho (2003). Responses of different arabica coffee (Coffea arabica L.) clones to varied environmental conditions. Euphytica. 129, 175-182.

Wintgens, J.N. (2004). Coffee bean quality assessment. In: Wintgens, J.N. (Ed.), Coffee: Growing, Processing, Sustainable Production. WILEY-VCH Verlag GmbH \& Co. KGaA, Weinheim.

Worku, M.; B. De Meulenaer \& L. Duchateau. (2017). PT CR. Food Research International.
Yahmadi, M. (1973). Pengaruh kemarau panjang terhadap tanaman kopi. Menara Perkebunan, 41, 235-240.

Yonas, B.; B. Bayetta \& F. Chemeda (2014). Performance evaluation of indigenous Arabica coffee genotypes across different environments. Journal of Plant Breeding and Crop Science, 6, 171-178.

$* * 0 * *$ 
Performance of biochemical compounds and cup quality of Arabica coffee

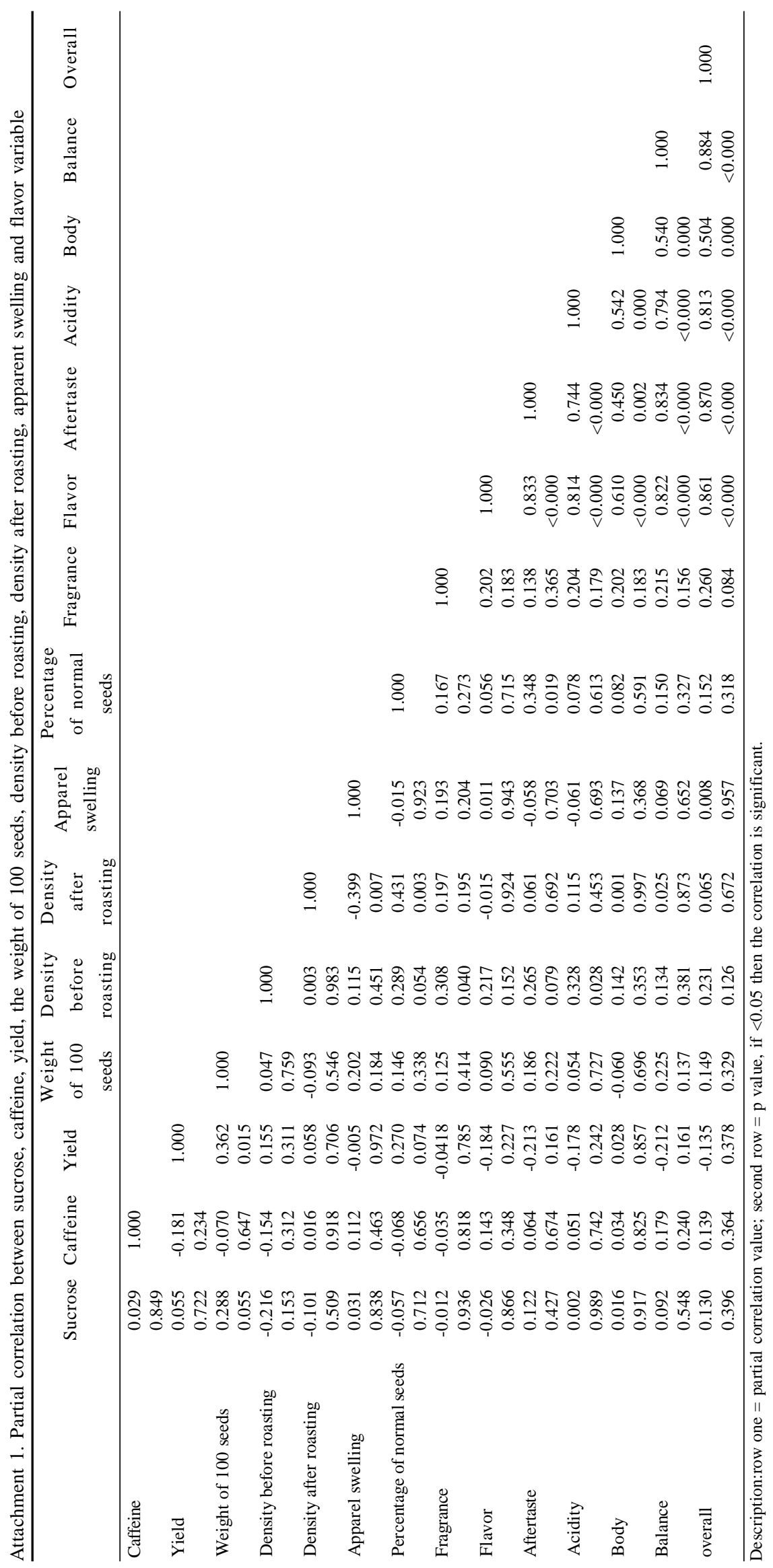

